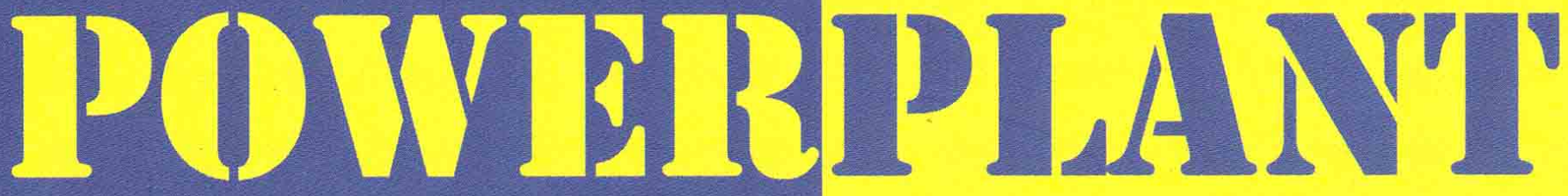

Nofirman:

Yusuf Rasyid

Vendy Antono;

Win Alfalah;

Rizky Windani

Eko Sulistiyo:

Utami Wahyuningsih:

M. Arif Rahman Sutisna

Sahlan

Vendy Antono;

Arief Suardi Nur Chairat;

Muhammad Husnuddin

Prayudi:

Roswati Nurhasanah

Hendri;

Suhengki:

Amru Fathony Lubis

Sri Yayi:

Jumiati;

Intan Ratna Sari Yanti
Pengaruh Kegagalan Terhadap Kinerja Chiller

Analisa Kegagalan Platen Tube SUperheater PLTU Teluk Sirih

Analisis Head Losses Pada Penstok Unit III Di Perum Jasa Tirta II Unit Jasa Pembangkit PLTA Ir. H.Djuanda

Kajian Terkait Industri Material HANKAM Dan

Kebencanaan Dari Sisi Pasar

Analisa Kerusakan Roda Gigi Cacing Pada Gearbox Air Preheater PLTU UJP Banten 3 Lontar Unit 1

Studi Eksperimental Kinerja Clod Strorage Mini dengan Refrigerant R2 dan R404A

Pengaruh Fouling Terhadap Laju Perpindahan Panas Pada Superheater Boiler CFB PLTU Sebalang

Pengaruh Jenis Pengetahuan Dan Kecakapan Terhadap Kemampuan Menulis Bahasa Inggris Pada Mahasiswa Teknik Mesin Sekolah Tinggi Teknik PLN

\begin{tabular}{|c|c|c|c|c|c|c|}
\hline$\|\mid\|$ & & SE & OLAH & VGGI TEKI & PL & \\
\hline
\end{tabular}




\title{
ANALISIS HEAD LOSSES PADA PENSTOCK UNIT III DI PERUM JASA TIRTA II UNIT JASA PEMBANGKIT PLTA IR. H. DJUANDA
}

\author{
Eko Sulistiyo $^{1, a}$, Utami Wahyuningsih ${ }^{2, b}$, M. Arif Rahman Sutisna ${ }^{3, c}$ \\ 1,2,3 Jurusan Teknik Mesin STT-PLN, Menara PLN Jl. Lingkar Luar Barat Duri Kosambi Cengkareng \\ Jakarta Barat Indonesia, 11750 \\ a ekosalma123@yahoo.com ; ${ }^{\mathbf{b}}$ wahyuningsih_utami@yahoo.com \\ ; ${ }^{\mathbf{c}}$ m.arif.rahman.sutisna@gmail.com
}

\begin{abstract}
One of the power plants in the labor system is hydropower, which is a power plant by utilizing water resources as its working fluid. In the operation of the hydropower requires high reliability so that the energy production contuinitas to the load center or to the power system network can be more optimum. One of the components in the hydropower plant is penstock. Closed pipeline, whether it is laminar or turbulent, must have head losses. Head losses on penstock is a phenomenon of losses on the penstock so as to make the head value on the hydropower becomes reduced. At Penstock unit III PLTA Ir. H. Djuanda there are two phenomenon of head losses, namely: head losses major caused by friction penstock against water and minor head losses in the form of bend $90^{\circ}$ with radius $4.375 \mathrm{~m}$ and $11.3 \mathrm{~m}$ from the axis penstock. Temperature changes affect the size of head losses, but they do not significantly affect penstock efficiency. At a temperature of $240 \mathrm{C}$ and a flow rate of $5 \mathrm{~m} / \mathrm{s}$ obtained a total head losses of $0606 \mathrm{~m}$ so as to make the potential of turbine inlet power down to 31,247 MW or $99.21 \%$.
\end{abstract}

Keyword: Penstock, Head Losses Major. Head Losses Minor, Penstock Efficiency

\section{Pendahuluan}

Energi listrik merupakan kebutuhan yang sangat penting bagi kehidupan manusia. Dengan semakin berkembang teknologi maka kebutuhan energi listrik akan meningkat. Namun, pemerintah indonesia belum bisa memenuhi kebutuhan listrik Indonesia. Pada tahun 2015 rasio elektrifikasi di Indonesia pada desa sebesar $96,94 \%$, sedangkan pada rumah tangga sebesar $88,30 \%$, tercatat masih terdapat masyarakat yang belum menikmati listrik. Sehingga pemerintah indonesia melalui Badan Usaha Milik Negara (BUMN) di bidang ketenaga listrikan terus melakukan pembangunan pembangkit listrik guna memenuhi kebutuhan listrik di Indonesia [1].

Energi listrik dapat dihasilkan dari beberapa energi yang diubah atau dikonversikan menjadi energi listrik dengan melalui beberapa proses. Pembangkit Listrik Tenaga Air (PLTA) memproduksi listrik yang dihasilkan dari mengkonversi energi potensial air. Energi potensial air ini digunakan untuk menggerakkan turbin yang kemudian turbin tersebut terhubung dengan generator, yang kemudian dengan beberapa proses yang terjadi, generator yang berputar menghasilkan energi listrik. Tercatat pada tahun 2015 kapasitas yang terpasang Pembangkit Listrik Tenaga Air (PLTA) Nasional di Indonesia sebesar 5.079,06 MW dengan persentase $9,15 \%$ dari Pembangkit Tenaga Listrik yang terpasang secara Nasional [1].

Pembangkit Listrik Tenaga Air (PLTA) memiliki keunggulan dibandingkan pembangkit listrik dengan menggunakan sumber energi lain. PLTA memanfaatkan energi air sebagai energi utama untuk menghasilkan listrik. Sehingga, PLTA merupakan pembangkit listrik dengan mengeluarkan biaya yang murah dibandingkan dengan menggunakan energi lainnya yang harus mengeluarkan biaya yang tinggi untuk menghasilkan listrik.

Di Pembangkit Listrik Tenaga Air (PLTA) Ir. H. Djuanda menggunakan turbin francis sebanyak 6 unit dengan kapasitas daya mampu masing-masing sebesar 32.3 MW dapat memproduksi listrik rata-rata dalam setahun sebesar 900 juta kWh. Peran PLTA Ir. H. Djuanda memproduksi listrik di seluruh Indonesia sebesar $0,51 \%$.

Di sebuah PLTA dibutuhkan sistem pemipaan. Sistem pemipaan adalah sistem yang 
digunakan untuk memindahkan fluida (baik cair maupun gas) dari suatu tempat ke tempat lain. Di Pembangkit Listrik Tenaga Air (PLTA) Ir. H. Djuanda, digunakan 6 unit penstock (sistem pemipaan) yang dibuat dari plat baja AQ UNI 815 dengan tebal $20 \mathrm{~mm}$ yang terletak di dalam dinding beton yang berfungsi untuk mengalirkan air dari waduk melalui pintu pengambilan ke turbin.

Di dalam sebuah sistem pemipaan pasti akan terjadi head losses (kerugian akibat adanya gesekan), adapun faktor yang mempengaruhi kerugian aliran fluida di dalam pipa adalah kecepatan aliran, luas penampang (pipa), friction factor, viskositas dan massa jenis fluida. Selain itu juga head losses akan berdampak pada daya turbin yang menurun.

Berdasarkan obeservasi ketika magang di Unit Jasa Pembangkitan PLTA Ir. H. Djuanda, maka penulis mendapatkan bahasan skirpsi dengan judul "Analisis Head Losses Pada Penstok Unit 1 Di Perum Jasa Tirta II Unit Jasa Pembangkitan PLTA Ir. H. Djuanda". Alasan dipilihnya judul tersebut yaitu untuk mengetahui penyebab dan besar head losses pada penstock unit 1 di PLTA Ir. H. Djuanda yang berdampak turunnya daya turbin.

\subsection{Pengertian PLTA}

Pembangkit listrik tenaga air adalah suatu pembangkit yang menggunakan media air sebagai pengerak utama (prime mover) untuk menggerakan turbin. Pembangkit ini secara umum mengkonversi bentuk perubahan dari tenaga air dengan ketinggian dan debit menjadi energi listrik dengan proses tertentu dan mengunakan komponen utama seperti waduk, turbin air, generator dan tranformator tenaga.

Mekanisme kerja PLTA bermula dengan urutan dari aliran sungai dengan sejumlah anak sungainya dibendung dengan sebuah Dam. Airnya ditampung dalam waduk yang kemudian dialirkan melalui Pintu Pengambilan Air (Intake Gate) yang selanjutnya masuk ke dalam Terowongan Tekan (Headrace Tunnel). Sebelum memasuki Pipa Pesat (Penstock), air harus melewati Tangki Pendatar (Surge Tank) yang berfungsi untuk mengamankan pipa pesat apabila terjadi tekanan kejut atau tekanan mendadak yang biasa disebut sebagai pukulan air (water hammer) saat Katup Utama (Inlet Valve) ditutup seketika. Setelah Katup Utama dibuka, aliran air memasuki Rumah Keong (Spiral Case). Aliran air yang bergerak memutar Turbin dan dari turbin, air mengalir keluar melalui Pipa Lepas (Draft Tube) dan selanjutnya dibuang ke Saluran Pembuangan (Tail Race). Poros turbin yang berputar tersebut dikopel dengan poros Generator sehingga menghasilkan energi listrik.

Melalui Trafo Utama (Main Transformer), energi listrik disalurkan melewati Saluran Udara Tegangan Tinggi (SUTT) $150 \mathrm{kV}$ dan $70 \mathrm{kV}$ ke konsumen melalui Gardu Induk.

\subsection{Kecepatan Aliran Fluida}

Karena adanya perbedaan diameter pada setiap pipa pesat maka kecepatan aliran yang terjadi berbeda-beda sesuai dengan adanya perubahan diameter tersebut. Dibawah ini nilai kecepatan aliran air akibat beda diameter ${ }^{[4]}$.

$$
\begin{gathered}
\text { Maka: } \\
\mathbf{V}=\frac{\mathbf{Q}}{\mathbf{A}}
\end{gathered}
$$

Dimana :

$\mathrm{Q}=$ Debit Air $\left(\mathrm{m}^{3} / \mathrm{s}\right)$

$\mathrm{V}=$ Kecepatan Aliran Fluida $(\mathrm{m} / \mathrm{s})$

$\mathrm{A}=$ Luas Penampang Pipa $\left(\mathrm{m}^{2}\right)$

\subsection{Bilangan Reynold}

Fungsi dari bilangan Reynold itu sendiri adalah untuk mengetahui jenis suatu aliran fluida yang ada di dalam pipa. Dibawah ini merupakan batasan nilai/harga bilangan Reynold untuk aliran internal flow dan disertai dengan jenis alirannya ${ }^{[6]}$ :

$\mathrm{Re}<2300$ maka alirannya adalah laminar $2300<\operatorname{Re}>4000$ maka alirannya adalah transisi

$\operatorname{Re}>4000$ maka alirannya adalah turbulen

Adapun persamaan untuk mendapatkan bilangan Reynold itu sendiri adalah :

$$
\operatorname{Re}=\frac{\dot{\boldsymbol{\rho}} \mathbf{v D}}{\boldsymbol{\mu}}
$$

Dimana :

$\mathrm{Re}=$ Bilangan Reynold

$\rho=$ Massa Jenis Fluida $\left(\mathrm{kg} / \mathrm{m}^{3}\right)$

$\mathrm{V}=$ Kecepatan Aliran Fluida $(\mathrm{m} / \mathrm{s}) \mathrm{D}=$ Diameter Pipa (m)

$\mu=\operatorname{Viskositas}$ Dinamik (N.s $\left./ \mathrm{m}^{2}\right)$

\subsection{Nilai Darcy Friction Factor $(f)$}

Setelah melakukan perhitungan bilangan Reynold, maka dapat dicari harga Darcy Friction Factor $(f)$, dengan cara menggunakan diagram Moody atau bisa menggunakan moody 
calculator yang akan. Faktor ini merupakan faktor gesekan pipa. Semakin pipa kasar, maka kemungkinan turbulent akan semakin besar.

\subsection{Head Losses Pada Penstock}

Dalam perhitungan head losses ini perlu diperhatikan beberapa faktor, karena dalam perhitungan head losses ini akan mempengaruhi daya yang akan dihasilkan oleh turbin. Dibawah ini merupakan persamaan yang digunakan untuk menghitung head pada turbin :

$$
\text { HT = Headstatic }- \text { Headlosses (m) }
$$

\section{Keterangan :}

Head static merupakan tinggi air jatuh dengan satuan meter $(\mathrm{m})$, yaitu dihitung dari permukaan air atas sampai permukaan air bawahnya.

Head losses merupakan rugi-rugi energi yang diakibatkan dari sistem pipa-pipa yang terpasang dengan satuan meter $(\mathrm{m})$.

Pada head losses ini terdapat dua jenis, yaitu head losses major dan head losses minor. Head losses itu sendiri merupakan penjumlahan dari head losses major dan head losses minor, seperti pada persamaan :

$$
H t=H L M a j o r+H L \text { Minor }
$$

Dimana :

$$
\begin{array}{ll}
\text { Ht } & =\text { Head Losses Total }(\mathrm{m}) \\
\text { HL Major } & =\text { Head Losses Major }(\mathrm{m}) \\
\text { HL Minor } & =\text { Head Losses Minor }(\mathrm{m})
\end{array}
$$

Head Losses Major, yaitu rugi- rugi energi yang diakibatkan dari gesekan fluida terhadap kekasaran permukaan bahan pipanya. Rumusan untuk menghitung Head Losses Major tersebut adalah ${ }^{[4]}$ :

$$
H L \cdot M a j o r=f \cdot \frac{\mathrm{L}}{\mathrm{D}} \cdot \frac{\mathrm{v} 2}{2 \mathrm{~g}}
$$

Dimana :

$$
\text { HL.Major = Head Losses Major (m) }
$$

$f=$ Koefisien gesekan

$L=$ Panjang pipa $(\mathrm{m})$

$D=$ Diameter pipa $(\mathrm{m})$

$V=$ Kecepatan rata-rata fluida $(\mathrm{m} / \mathrm{s})$

$\mathrm{g}=$ Percepatan gravitasi $\left(\mathrm{m} / \mathrm{s}^{2}\right)$

Head Losses Minor, yaitu rugi-rugi energi yang diakibatkan karena terdapat belokan-belokan atau sambungan-sambungan pada sistem perpipaannya. Dengan persamaan rumus Fuller untuk menghitung koefisien gesekan belokan adalah ${ }^{[6]}$ :

$$
\mathrm{K}=\left[0.131+1.847\left(\frac{\mathrm{D}}{2 \mathrm{R}}\right)^{\mathbf{3 . 5}}\right]\left(\frac{\boldsymbol{\theta}}{90}\right)^{\mathbf{0 . 5}}
$$

Kemudian untuk mengetahui head losses minor menggunakan persamaan dibawah ini ${ }^{[6]}$ :

$$
\text { HL.Minor }=\mathrm{K} \frac{\mathrm{V}^{2}}{2 . \mathrm{g}}
$$

Dimana ;

HL.Minor = Head Losses Minor (m)

$\mathrm{K}=$ Nilai koefisien gesekan dari belokan atau sambungan

$f=$ Koefisien gesekan

$L e=$ Panjang ekivalen pipa $(\mathrm{m})$

$D=$ Diameter pipa $(\mathrm{m})$

$\mathrm{V}=$ Kecepatan rata-rata fluida $(\mathrm{m} / \mathrm{s})=$ Percepatan gravitasi $\left(\mathrm{m} / \mathrm{s}^{2}\right)$

\subsection{Mencari Effisiensi Penstock}

Untuk mencari efisiensi penstock diperlukan perhitungan sebagai berikut:

\section{Daya Hidrolis Air}

Daya hidrolis air adalah daya air yang mampu air ciptakan tanpa dikurangi kerugiankerugian (Head Losses) pada penstock. Persamaan daya hidrolis air sebagai berikut:

$$
\mathbf{P H}=\boldsymbol{\rho} \times \mathbf{g} \times \mathbf{Q} \times \mathbf{H}
$$

Dimana :

$$
\begin{aligned}
\mathrm{PH} & =\text { Daya hidrolis air }(\mathrm{watt}) \\
\mathrm{P} & =\text { Massa jenis air }\left(\mathrm{kg} / \mathrm{m}^{3}\right) \\
\mathrm{g} & =\text { Percepatan gravitasi }\left(\mathrm{m} / \mathrm{s}^{2}\right) \mathrm{Q}=\text { Debit air } \\
& \text { yang masuk }\left(\mathrm{m}^{3} / \mathrm{s}\right) \\
\mathrm{H} & =\text { Tinggi jatuh air (elevasi) }(\mathrm{m})
\end{aligned}
$$

\section{Daya Losses Penstock}

Daya losses penstock adalah jumlah potensi daya yang hilang karena kerugian-kerugian (Head Losses). Dengan persamaan sebagai berikut:

$$
P L=\rho \times g \times Q \times H T
$$

Dimana:

$$
\begin{aligned}
\mathrm{PL}= & \text { Daya losses penstock (watt) } \\
\rho= & \text { Massa jenis air }\left(\mathrm{kg} / \mathrm{m}^{3}\right) \\
\mathrm{g}= & \text { Percepatan gravitasi }\left(\mathrm{m} / \mathrm{s}^{2}\right) \mathrm{Q}=\text { Debit air } \\
& \text { yang masuk }\left(\mathrm{m}^{3} / \mathrm{s}\right) \mathrm{HT}=\text { Head losses } \\
& \text { total penstock }(\mathrm{m})
\end{aligned}
$$




\section{Daya Masuk Turbin}

Daya masuk turbin adalah potensi daya yang dapat dihasilkan dari penstock setelah dikurangi kerugian-kerugian (Head Losses). Dengan persamaan sebagai berikut:

$$
\mathbf{P}_{\mathrm{T}}=\mathbf{P H}-\mathbf{P L}
$$

Dimana:

$\mathrm{P}_{\mathrm{T}}=$ Daya masuk turbin (watt)

$\mathrm{PH}=$ Daya hidrolis air (watt)

$\mathrm{PL}=$ Daya losses penstock (watt)

\section{Efisiensi Penstock}

Setelah tiga perhitungan (Daya Hidrolis Air, Daya Losses Penstock, Daya Masuk Turbin) didapat, maka dapat dihitung effisiensi penstock dengan persamaan sebagai berikut:

$$
\eta \mathbf{p}=\frac{\mathbf{P}_{\mathrm{T}}}{\mathbf{P}_{\mathrm{H}}} \times 100 \%
$$

Dimana:

$\eta \mathbf{p}=$ Efisiensi penstock

$\mathrm{PT}=$ Daya masuk turbin (MegaWatt)

$\mathrm{PH}=$ Daya hidrolis air (MegaWatt)

\section{Metodologi Penellitian}

Metode penelitian ini sangat membantu penulis dalam melakukan penyusunan skripsi. Karena penulis dapat melakukan penelitian dengan benar karena sudah terdapat langkah langkah yang akan digunakan dalam melaksanakan penelitian. Dalam skripsi ini penulis menggunakan metode deskriptif dimana metode ini biasa digunakan dalam penulisan skripsi fakultas teknik. Dimana metode deskriptif yang digunakan penulis memiliki tujuan untuk melakukan analisis dan perhitungan head losses pada penstock, karena dalam skripsi ini penulis memiliki judul "Analisis Head Losses Pada Penstok Unit III Di Perum Jasa Tirta II Unit Jasa Pembangkitan PLTA Ir. H. Djuanda" yang dilakukan Di Perum Jasa Tirta II Unit Jasa Pembangkitan PLTA Ir. H. Djuanda.

Penelitian dilakukan selama 3 bulan (4 September 2017 - 4 September 2017). Lokasi penelitian dilakukan di Unit 2 PLTGU yang terletak di Kecamatan Jatiluhur, Kabupaten Purwakarta, Provinsi Jawa Barat $( \pm 9 \mathrm{~km}$ dari pusat Kota Purwakarta).

Untuk mempermudah pemahaman yang dilakukan penelitian, maka di gunakan flow chart sebagai berikut :

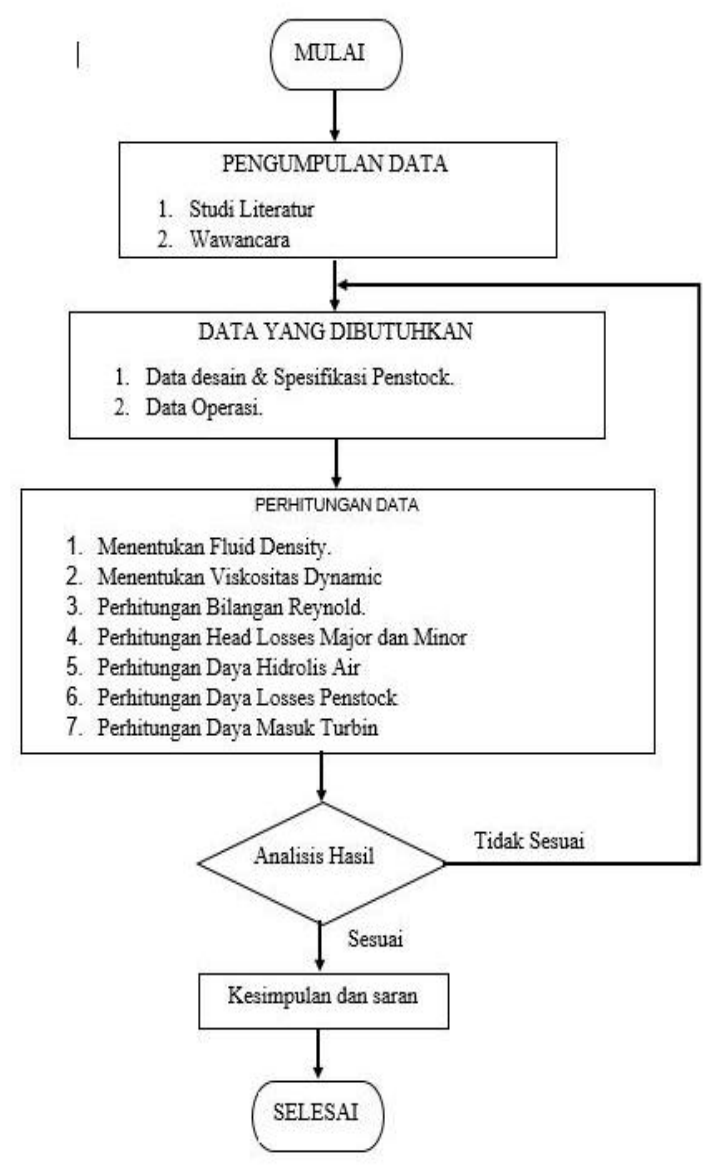

\section{Hasil dan Pembahasan}

\subsection{Hasil Perhitungan}

Berikut merupakan gambar penstock pada PLTA Ir. H. Djuanda

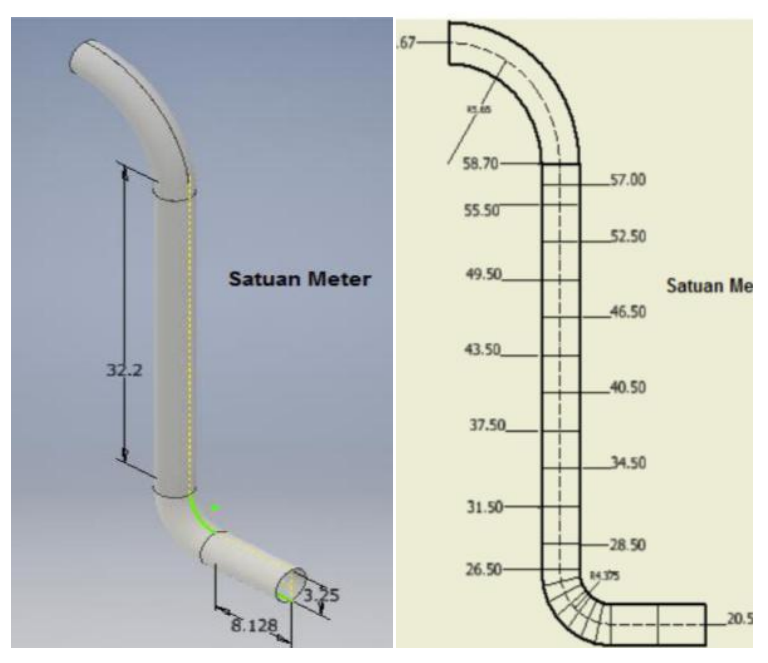


Effisiensi penstock unit III PLTA Ir. H. Djuanda:

\begin{tabular}{|c|c|c|c|c|c|c|c|}
\hline$\underset{\left({ }^{\mathrm{N}} \mathrm{C}\right)}{\mathrm{T}}$ & $\begin{array}{c}\mathbf{V} \\
(\mathrm{m} / \mathrm{s})\end{array}$ & $\begin{array}{l}\text { HL major } \\
(\mathrm{m})\end{array}$ & $\begin{array}{l}\text { HL Minor } \\
\text { (m) }\end{array}$ & $H_{t}(\mathbf{m})$ & Рн (MW) & $\mathbf{P}_{\mathrm{T}}(\mathbf{M W})$ & $\eta \mathrm{p}(\%)$ \\
\hline 24 & 1 & 0.01141 & 0.009618 & 0.024692 & 6.2495 & 6.2475 & 99.96793 \\
\hline 26 & 1 & 0.01139 & 0.009618 & 0.024672 & 6.2463 & 6.2443 & 99.96795 \\
\hline 28 & 1 & 0.01137 & 0.009618 & 0.024662 & 6.2429 & 6.2409 & 99.96797 \\
\hline 30 & 1 & 0.01134 & 0.009618 & 0.024632 & 6.2393 & 6.2373 & 99.96801 \\
\hline 24 & 3 & 0.09809 & 0.086559 & 0.217945 & 18.7484 & 18.6953 & 99.71695 \\
\hline 26 & 3 & 0.09790 & 0.086559 & 0.217885 & 18.7388 & 18.6858 & 99.71703 \\
\hline 28 & 3 & 0.09791 & 0.086559 & 0.217815 & 18.7287 & 18.6757 & 99.71712 \\
\hline 30 & 3 & 0.09781 & 0.086559 & 0.217745 & 18.7178 & 18.6649 & 99.21321 \\
\hline 24 & 5 & 0.26942 & 0.240443 & 0.60583 & 31.2474 & 31.0015 & 99.213207 \\
\hline 26 & 5 & 0.26916 & 0.240443 & 0.60564 & 31.2314 & 30.9858 & 99.21345 \\
\hline 28 & 5 & 0.26911 & 0.240443 & 0.6056 & 31.2145 & 30.969 & 99.21351 \\
\hline 30 & 5 & 0.26891 & 0.240443 & 0.60546 & 31.1963 & 30.951 & 99.21369 \\
\hline
\end{tabular}

\subsection{Analisis Data}

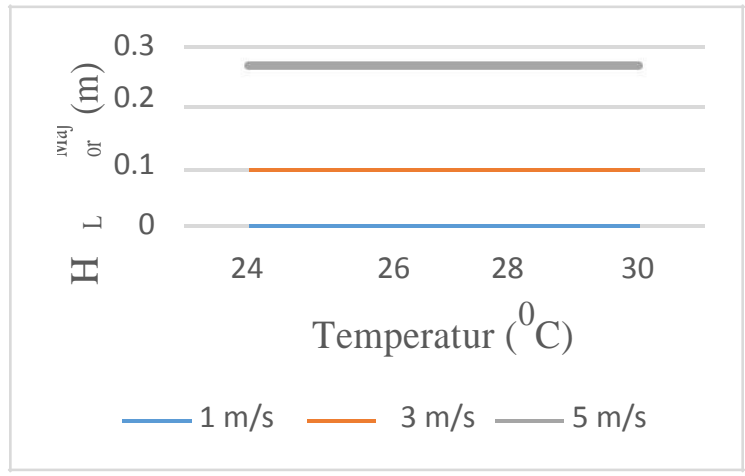

Pada grafik diatas menunjukkan pengaruh temperatur air dan kecepatan aliran air terhadap head losses major. Pada kecepatan aliran yang tetap, semakin tinggi temperatur air maka ada penurunan head losses major yang tidak terlalu besar dengan rata-rata penurunan sebesar $0.00002 \mathrm{~m}-0.00007 \mathrm{~m}$. Pada temperatur air yang sama, semakin tinggi kecepatan aliran maka semakin besar head losses major cukup signifikan. Hal ini karena berdasarkan tabel 4.9 semakin tinggi temperatur air juga kecepatan aliran air, maka semakin kecil darcy fiction factor.

Besar head losses major berbanding lurus dengan nilai darcy fiction factor dan pangkat kuadrat terhadap kecepatan aliran.

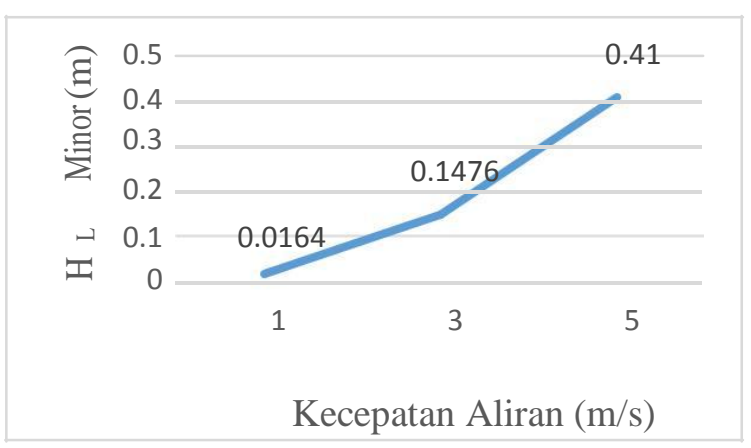

Berdasarkan grafik diatas dapat disimpulkan berapapun temperatur air tidak mempengaruhi besarnya head losses minor. Head losses minor dipengaruhi oleh kecepatan aliran air. Semakin tinggi kecepatan aliran air maka semakin tinggi head losses minor.

Head losses total merupakan hasil jumlah dari head losses major dengan head losses minor. Head losses terbesar terjadi saat kecepatan aliran $5 \mathrm{~m} / \mathrm{s}$ dan temperature air $24^{\circ} \mathrm{C}$ dengan nilai head losses total sebesar 0.60546 $\mathrm{m}$. Semakin tinggi temperatur air pada kecepatan yang sama, maka semakin kecil head total. Semakin tinggi kecepatan aliran air, maka semakin besar head total. Head losses total mengurangi potensi daya air yang masuk ke penstock. 


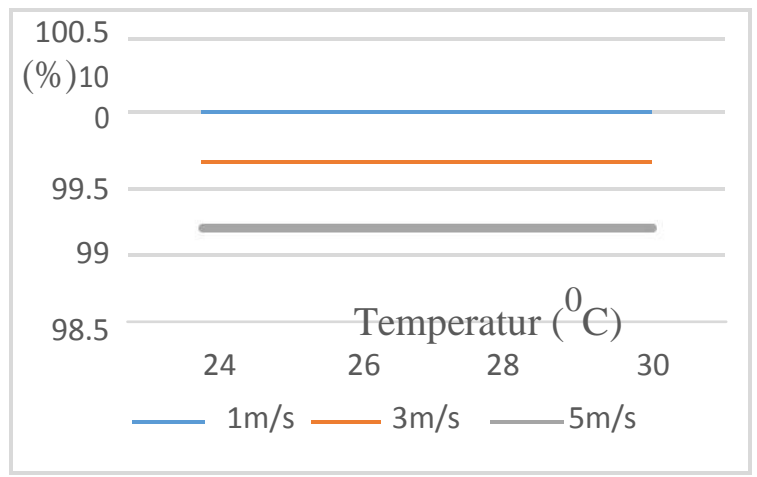

Dari grafik diatas dapat disimpulkan bahwa semakin tinggi kecepatan aliran air pada penstock, maka semakin kecil effisiensi penstock. Namun perbedaan temperatur air hanya berpengaruh sangat kecil terhadap effisiensi penstock.

\section{Kesimpulan Dan Saran}

\subsection{Kesimpulan}

Setelah melakukan pembahasan dan melakukan analisa terhadap data hasil perhitungan, dapat diambil kesimpulan sebagai berikut :

1. Pada penstock unit III PLTA Ir. H. Djuanda terdapat 2 macam head losses, yaitu: head losses major yang disebabkan oleh faktor gesekan dari bahan pipa dengan air yang mengalir pada penstock dan head losses minor berupa dua buah belokan $90^{\circ}$ dengan jari-jari $4.375 \mathrm{~m}$ dari sumbu penstock dan belokan $90^{\circ}$ dengan jari-jari $11.3 \mathrm{~m}$ dari sumbu penstock. Temperatur dan kecepatan aliran air pada penstock mempengaruhi besarnya head losses. Semakin tinggi temperatur air dengan kecapatan aliran yang sama, maka head losses semakin kecil. Pada kecepatan aliran $1 \mathrm{~m} / \mathrm{s}$ dan temperatur $24^{0} \mathrm{C} ; 30^{\circ} \mathrm{C}$ didapat head losses sebesar: $0.024692 \mathrm{~m} \quad ; 0.024672 \mathrm{~m}$. Semakin tinggi kecepatan aliran dengan temperatur air yang sama, maka semakin besar head losses. Pada temperatur air $24^{\circ} \mathrm{C}$ dan kecepatan aliran air $1 \mathrm{~m} / \mathrm{s} ; 5 \mathrm{~m} / \mathrm{s}$ didapat head losses sebesar: $0.024692 \mathrm{~m}$; $0.60583 \mathrm{~m}$.

2. Semakin besar kecepatan aliran air pada penstock, maka semakin kecil effisiensi penstock. Terbukti Effisiensi penstock terkecil didapat pada kondisi kecepatan aliran $5 \mathrm{~m} / \mathrm{s}$ sebesar $99.21368 \%$ dan effisiensi penstock terbesar pada kondisi aliran $1 \mathrm{~m} / \mathrm{s}$ sebesar $99.9679 \%$. Keadaan temperatur air tidak mempengaruhi secara signifikan terhadap effisiensi penstock. Terbukti bahwa head losses pada penstock mengurangi daya masuk turbin menjadi $99.21368 \%$.

3. Besarnya effisiensi penstock unit III PLTA Ir. H. Djuanda memiliki nilai yang cukup besar, sehingga bisa memaksimalkan potensi air pada waduk PLTA Ir. J. Djuanda.

\subsection{Saran}

Penulis membuat beberapa saran agar efisiensi penstock unit III PLTA Ir. H. Djuanda dapat dipertahankan, yaitu:

1. Selalu tetap menjaga cat pelindung Bitusealac setebal 700 mikron dengan cara: selalu mengganti cat pelindung selama lima tahun sekali sesuai dengan pedoman pemeliharaan PLTA Ir. H. Djuanda, juga tidak mengoperasikan PLTA Melebihi kecepatan aliran maksimum sesuai dengan ketahanan cat pelindung sebesar $5 \mathrm{~m} / \mathrm{s}$. Hal ini dilakukan untuk menjaga nilai relatif roughness dari bahan penstock.

2. Selalu membersihkan dan merawat filter pada intake untuk mengurangi kemungkinan masuknya benda asing ke dalam penstock yang akan merusak permukaan dalam penstock dan mengurangi effisiensi penstock.

\section{Referensi}

[1] Statistik Ketenagalistrikan Direktorat Jenderal Kelistrikan Kementrian ESDM Edisi No.29 Tahun Anggaran 2016.

[2] Kadir, Abdul. 2010. Pembangkit Tenaga Listrik (Edisi Revisi). Jakarta: UI Press.

[3] Administrator. 2017. eProfil Perusahaan PERUM Jasa Tirta II. Diakses pada tanggal 14 September 2017 dari http://jasatirta2.co.id/sejarah

[4] Munson R. Bruce, Young F. Donald, Theodore. Okiishi. 2005. Mekanika Fluida Edisi Keempat .Jakarta : Erlangga. White, Frank M. 2003. Fluid Mechanics fifth edition. Bangkok: WCB MCGraw-Hill.

[5] Sularso dan Tahara, H., 2006, Pompa dan Kompresor, Pemilihan,Pemakaian,dan Pemeliharaan, PT Pradnya Paramita, Jakarta. 
[6] Ramadhan, Irfan Muhammad dan Syuriadi, Adi. 2016. "Analisa Faktor Head Losses Penstock Terhadap Daya Yang Dihasilkan Di PLTA Saguling”.

[7] Manumpak, Richard dan Warman, Eddy. 2013. "Perancangan Instalasi Aliran Air PLTA Renun Guna Peningkatan Daya Keluaran Generator Sinkron".

[8] Djuanda Pedoman Operasi Dan Pemeliharaan Pembangkit Listrik Tenaga Air (PLTA) Jilid 2. Purwakarta. 2002

[9] CRC Handbook of Chemistry and Phsyics, 84 ${ }^{\text {th }}$ edition, 2003-2004

[10] www.engineeringtoolbox.com 